1 Cunningham-Burley S, Maclean V. The role of the chemist in primary health care for children with minor complaints. Soc Sci Med 1987;24:371-7.

Morrell DC. Teaching patients to look after themselves. From the postgraduate centres. Updale November 1981 1:1187-95.

Gallager F, Zander L. General practitioner and the pharmacist. $B M{ }^{2}$ 1983;287:397-8.

4 Mobey N, Wood A, Edwards C, Jepson MH. An assessment of the response to symptoms in community pharmacies. Pharmaceutical fournal 1986;3:807.

5 London, Royal Pharmaceutical Society of Great Britain. Medicine and ethics: a guide for pharmacists. London: RPS, 1989.

6 Edwards C, Stillman P. Minor illness or major disease? London: Pharmaceutical Press, 1982.

Waterston T, Ledez $\mathrm{K}$. What medical treatment do parents use at home? fournal of Maternal and Child Health, 1981;1:34-7.

World Health Organisation. A manual for the treatment of acute diarrhoea. Geneva: WHO, 1980. (CDD/SER/80.2.)

9 Rylance GW, Woods GC, Cullen RE, Rylance ME. Use of drugs by children. BMF 1988;297:445-7.
10 Pauncefor Z, Zeelenberg S. Pharmacy health care: a report on the scheme to provide free leaflets and information on major health care issues from commumiy pharmacies. London: Family Planning Association, 1989

11 Cutting WAM. Self-prescribing and promotion of anti-diarrhoeal drugs Lancet 1989;i:1080-1.

12 Wharton BA, Pugh RE, Taitz LS, Walker-Smith JA, Booth IW. Dietary management of gastroenteritis in Britain. BMJ 1988;296:450-2.

13 Walker-Smith JA. Management of infantile gastroenteritis. Arch Dis Child 1990;65:917-8

14 Khin-Maung-U, Nyunt-Nyunt-Wai, Myo-Khin, Mu-Mu-Khin, Tin-U, Thane-Toe. Effect on clinical outcome of breast feeding during acute diarrhoea. BMF 1985;290:587-9.

15 Conway SP, Ireson A. Acute gastroenteritis in well nourished infants: comparison of four feeding regimens. Arch Dis Child 1989;64:87-91.

\title{
Incidence of insulin dependent diabetes in children aged under 15 years in the British Isles during 1988
}

\author{
M Alison Metcalfe, J David Baum
}

Abstract

Objective-To ascertain the annual incidence rate of insulin dependent diabetes diagnosed in children under the age of $\mathbf{1 5}$ years in the British Isles during 1988 , and to compare the results with an earlier study carried out in 1973-4.

Design-Active monthly reporting of cases by consultant paediatricians, with additional input from diabetologists and all specialist diabetes nurses and health visitors.

Setting-British Isles (England, Wales, Scotland, Northern Ireland, Republic of Ireland) with a total population at risk of 11819000 children.

Patients - All children diagnosed under the age of 15 years with primary insulin dependent diabetes from 1 January to 31 December 1988 and resident in the British Isles at diagnosis.

Main outcome measures-National incidence rate of insulin dependent diabetes; differences in incidence rates between regions and between three age groups: 4 and under, 5-9, and 10-14 year olds.

Results -1600 children ( 837 boys and 763 girls) had a confirmed diagnosis of insulin dependent diabetes, giving a national incidence rate of 13.5/ 100000 /year $(95 \%$ confidence interval 12.9 to 14.2 / $100000 /$ year). This was considerably higher than the incidence rate of $7 \cdot 7 / 100000 /$ year in children under the age of 16 years reported in the British Diabetic Association's study of 1973-4. The age-sex adjusted rates varied between regions, ranging from $6.8 /$ $100000 /$ year (Republic of Ireland) to $19 \cdot 8 / 100000 /$ year(Scotland). There were considerable differences in the numbers of cases diagnosed each month, with the 10-14 year age group showing the most seasonal variation. A quarter of the children $(404 / 1600)$ were under 5 years old. Case ascertainment was estimated as $90 \%$.

Conclusions-Insulin dependent diabetes in the British Isles does not seem to occur uniformly over time or geographical area. Even allowing for differences in ascertainment between the 1973-4 and 1988 studies, there seems to have been an increase in the incidence rate of insulin dependent diabetes in children under the age of 15 years during the 15 year time period. If diabetes is becoming more common in this age group, possibly by developing earlier in susceptible children, this would be a matter of considerable public health concern.

Introduction

Internationally there are considerable differences in the reported incidence rates of insulin dependent diabetes in children, the highest being in Finland $(28 \cdot 6 / 100000 / \text { year })^{1}$ and the lowest in Japan (1.7/ $100000 /$ year). ${ }^{2}$ The size of these differences suggests the influence of environmental factors over and above any differences in genetic predisposition.

There has been no study on the incidence of insulin dependent diabetes in the British Isles since data from the British Diabetic Association register relating to 1973 and 1974 were published. ${ }^{3}$ This gave a mean incidence rate of $7 \cdot 7 / 100000$ /year for children under the age of 16 years at diagnosis. Subsequently, reports from Scotland ${ }^{45}$ and Leicestershire ${ }^{6}$ have suggested that the incidence rate in children in those areas has been increasing over the past $30-40$ years. We therefore studied the incidence of insulin dependent diabetes in children under 15 years of age in the British Isles.

\section{Methods}

Ethical approval for this national study was obtained from the BMA and the Bristol and Weston District Health Authority. The study protocol was also scrutinised and found to be acceptable by the ethics advisory committee of the British Paediatric Association.

New cases of children with insulin dependent diabetes diagnosed from 1 January to 31 December 1988 who received insulin treatment before their 16th birthday were reported by consultant paediatricians to the British Paediatric Surveillance Unit in London. This is an active reporting system that involves all paediatricians in the surveillance of certain serious childhood diseases. ${ }^{7}$ A report card containing a list of conditions is sent monthly to the 850 consultant paediatrician members of the British Paediatric Association and other categories of member where appropriate. The respondents are asked to report cases of conditions named on the card that they have seen in the preceding month or to check a "nil-return" box. Diabetes mellitus was included on the card for 12 months (February 1988 to January 1989). Most children were admitted to hospital at diagnosis, but even if treatment for some children had been started at home a hospital based consultant paediatrician was responsible for their care.

When a case was reported to the surveillance unit the information was sent to the study administrator (MAM) in Bristol. Each reporting paediatrician was asked to confirm that case, give some additional details, and provide permission to approach firstly the general practitioner and then the parents of each child with newly diagnosed diabetes with a short questionnaire. (The results from the questionnaire data will be 
published separately.) After the last cases had been reported (January 1989) consultants were sent the names of the children whom they had identified and asked to add any new cases diagnosed in 1988 under their care that had been overlooked. Additionally, all the nurses and health visitors whose names appeared in the Directory of Nurses with a Special Interest in Diabetes ${ }^{8}$ were contacted (through the British Diabetic Association) and asked to list all children under 16 years of age known to them who had diabetes diagnosed during 1988. The study was publicised through the medical and scientific section of the British Diabetic Association, and in Balance, the British Diabetic Association magazine. Physicians (responsible for the care of some of the older children) were also encouraged to report cases.

Special arrangements were made for children with diabetes diagnosed in Scotland and in the Oxfordshire Regional Health Authority, where separate studies were already continuing: the Scottish Study Group for the Care of Young Diabetics' and the Bart's-Oxford family study. ${ }^{10}$ These cases were reported to the surveillance unit in the usual way, but further details about each case were provided directly by the administrators of the Scottish Study Group for the Care of Young Diabetics and Bart's-Oxford family study, and questionnaires were not sent to the parents.

The British Isles (total population about 60600000 with about 11819000 children (19\%) aged under 15 years in 1988) were divided into 18 areas based on the current regional health authorities: 14 in England, with Wales, Scotland, Northern Ireland, and the Republic of Ireland making up the remaining four. For ease of administration three cases from the Isle of Man and three from the Channel Islands were included in the totals for the Northern and Wessex Regional Health Authorities respectively. We know of two children with newly diagnosed diabetes who died in 1988; they were included in the analysis.

Excluded from the analysis were 10 children whose diabetes was secondary to cystic fibrosis or steroid treatment and one baby who had transient insulin requiring diabetes but had not needed insulin again by the end of 1988 . Also excluded were 51 cases which had been reported initially but subsequently not confirmed by consultant paediatricians. This analysis was restricted to confirmed new cases diagnosed before the 15th birthday to make the data comparable with published reports on the incidence of insulin dependent childhood diabetes elsewhere in the world.

Incidence rates for ages 14 years and under were

TABLE I - Population at risk from diabetes, observed and expected number of cases, standardised morbidity ratios, adjusted for age and sex, and the age-sex adjusted incidence rates for each regional health authority or area

\begin{tabular}{|c|c|c|c|c|c|c|}
\hline \multirow[b]{2}{*}{$\begin{array}{l}\text { Map } \\
\text { key }\end{array}$} & \multirow[b]{2}{*}{ Region } & \multirow[b]{2}{*}{$\begin{array}{l}\text { Population } \\
<15 \text { years old }\end{array}$} & \multicolumn{2}{|c|}{ No of cases } & \multirow{2}{*}{$\begin{array}{c}\text { Standardised } \\
\text { morbidity ratio }(95 \% \\
\text { confidence interval })\end{array}$} & \multirow{2}{*}{$\begin{array}{c}\text { Age-sex adjusted } \\
\text { incidence rates } \\
\text { (per } 100000)\end{array}$} \\
\hline & & & Observed & Expected & & \\
\hline $\mathrm{S}$ & Scotland & 956000 & 190 & 130 & 146 (137 to 155$)$ & $19 \cdot 8$ \\
\hline $\mathrm{D}$ & East Anglian & 384000 & 68 & 52 & 131 (117 to 145$)$ & $17 \cdot 7$ \\
\hline $\mathrm{J}$ & Wessex & 549000 & 94 & 74 & $126(115$ to 138$)$ & $17 \cdot 1$ \\
\hline A & Northern & 588000 & 93 & 80 & $117(105$ to 128$)$ & $15 \cdot 8$ \\
\hline $\mathrm{N}$ & Mersey & 463000 & 73 & 63 & $116(104$ to 129$)$ & $15 \cdot 8$ \\
\hline $\mathrm{K}$ & Oxford & 497000 & 75 & 67 & $112(100$ to 124$)$ & $15 \cdot 2$ \\
\hline B & Yorkshire & 691000 & 103 & 93 & $110(100$ to 121$)$ & 14.9 \\
\hline $\mathrm{P}$ & North Western & 771000 & 112 & 104 & $108(98$ to 117$)$ & $14 \cdot 6$ \\
\hline $\mathrm{C}$ & Trent & 866000 & 117 & 117 & $100(90$ to 109$)$ & 13.5 \\
\hline $\mathrm{L}$ & South Western & 573000 & 77 & 78 & $99(88$ to 110$)$ & $13 \cdot 4$ \\
\hline$M$ & West Midlands & 1000000 & 133 & 135 & $98(90$ to 107$)$ & $13 \cdot 3$ \\
\hline $\mathrm{G}$ & South East Thames & 655000 & 85 & 88 & 96 (86 to 107$)$ & $13 \cdot 1$ \\
\hline $\mathrm{R}$ & Wales & 539000 & 69 & 73 & 94 (83 to 106 ) & $12 \cdot 8$ \\
\hline $\mathrm{H}$ & South West Thames & 519000 & 64 & 70 & $91(80$ to 103$)$ & $12 \cdot 4$ \\
\hline $\mathbf{F}$ & North East Thames & 703000 & 82 & 94 & $87(77$ to 97$)$ & $11 \cdot 8$ \\
\hline $\mathrm{T}$ & Northern Ireland & 396000 & 43 & 54 & 80 (67 to 94$)$ & $10 \cdot 9$ \\
\hline $\mathrm{E}$ & North West Thames & 644000 & 51 & 86 & $59(48$ to 70$)$ & $8 \cdot 0$ \\
\hline V & Republic of Ireland & 1025000 & 71 & 141 & $50(42$ to 59$)$ & $6 \cdot 8$ \\
\hline Total & & 11819000 & 1600 & & & \\
\hline
\end{tabular}

National incidence rate $=13 \cdot 5 / 100000 /$ year $(95 \%$ confidence interval $12 \cdot 9$ to $14 \cdot 2 / 100000 /$ year $)$. calculated using population data from the 1971 census for 1973-4 and mid-year estimates of population in each region for 1988 from the national general register offices. $^{11-20}$ Standardised morbidity ratios were calculated as described by Armitage and Berry, ${ }^{21}$ exact 95\% confidence intervals for age stratified incidence rates were obtained from Geigy scientific tables, ${ }^{22}$ and tests for seasonal trend were based on a method by Freedman. ${ }^{23}$ Analysis was performed using the statistical package for social sciences (SPSS), Lotus 1-2-3 and the generalised linear interactive modelling package.

We calculated a crude incidence rate for each region. Because the populations in each region differ for sex and age groups we adjusted for these using indirect standardisation by dividing the population of both sexes in each region into three age groups, 4 years and under, 5-9 years, and 10-14 years, and calculating the expected number of cases. The ratio of the observed to the expected number of cases multiplied by 100 is the standardised morbidity ratio for the region. ${ }^{21}$ The $95 \%$ confidence intervals for each regional standardised morbidity ratio were calculated; if the value for the standardised morbidity ratio of 100 was not included within the confidence interval we assumed that there was a significant difference between the incidence rates in the region and the rate throughout the country (the national incidence rate). Incidence rates adjusted for age and sex for each region were obtained by multiplying the incidence rate for the standard (national) population by the regional standardised morbidity rate/100. In fact, there was little difference between the regional crude and age-sex adjusted rates; the term "regional incidence rate" is used to refer to the age-sex adjusted rates for each region.

To try to validate the study we contacted the statistical officers of each region in England and Wales so that the computerised hospital activity analyses and patient information systems could be used to identify any cases not reported to the study. This inquiry proved untimely, coming so soon after the implementation of the Körner system in 1986, and the exercise was incomplete. Details relating to information from two regions are given in the appendix.

\section{Results}

Of the 1600 cases, $1412(88 \%)$ were confirmed by paediatricians, $132(8 \%)$ were reported by nurses (and confirmed by a doctor), $52(3 \%)$ were reported by physicians, and four $(<1 \%)$ were reported by mothers.

\section{NATIONAL INCIDENCE RATE}

The total number of confirmed cases of children with insulin dependent diabetes aged 14 years and under at diagnosis for the British Isles in 1988 was 1600 , giving a national incidence rate of $13 \cdot 5 / 100000 /$ year $(95 \%$ confidence interval 12.9 to $14 \cdot 2 / 100000$ / year). There were 837 boys and 763 girls; the male to female ratio was $1 \cdot 1: 1$, which was the same as the ratio for the population as a whole.

\section{REGIONAL INCIDENCE RATES}

Regional incidence rates varied considerably, with that of Scotland at $19 \cdot 8 / 100000 /$ year being almost triple that of the Republic of Ireland at $6 \cdot 8 / 100000 /$ year (table I). Five regions had rates significantly higher than the national incidence rate and four regions had rates significantly lower than the national rate (fig 1).

\section{AGE AT DIAGNOSIS}

A quarter (404) of the children were aged under 5 years, including 19 infants under the age of 1 year at diagnosis. A peak age specific incidence rate of around 


\begin{tabular}{|c|c|c|c|c|c|c|}
\hline \multirow[b]{2}{*}{ Age group (years) } & \multicolumn{2}{|r|}{ Boys } & \multicolumn{2}{|r|}{ Girls } & \multicolumn{2}{|r|}{ Total } \\
\hline & No $(\%)$ cases & $\begin{array}{l}\text { Incidence (per } 100000) \\
(95 \% \text { confidence interval })\end{array}$ & No (\%) cases & $\begin{array}{l}\text { Incidence (per } 100000) \\
(95 \% \text { confidence interval) }\end{array}$ & No $(\%)$ cases & $\begin{array}{l}\text { Incidence (per } 100000) \\
(95 \% \text { confidence interval) }\end{array}$ \\
\hline$\leqslant 4$ & $210(25)$ & $10 \cdot 0(8 \cdot 7$ to $11 \cdot 5)$ & $194(25)$ & $9 \cdot 7(8 \cdot 3$ to $11 \cdot 0)$ & $404(25)$ & $9 \cdot 9(9 \cdot 0$ to $10 \cdot 9)$ \\
\hline $\begin{array}{l}5-9 \\
5-9\end{array}$ & $264(32)$ & $12.9(11.4$ to 14.6$)$ & $264(35)$ & $13.6(12.0$ to $15 \cdot 4)$ & $528(33)$ & $13 \cdot 3(12 \cdot 2$ to $14 \cdot 5)$ \\
\hline $10-14$ & $363(43)$ & $18.8(16.9$ to 20.9$)$ & $305(40)$ & $16.7(14.9$ to $18 \cdot 7)$ & $668(42)$ & $17 \cdot 8(16 \cdot 5$ to $19 \cdot 2)$ \\
\hline Total & $837(100)$ & $13 \cdot 8(12 \cdot 9$ to $14 \cdot 8)$ & $763(100)$ & $13 \cdot 3(12 \cdot 4$ to $14 \cdot 3)$ & $1600(100)$ & $13 \cdot 5(12 \cdot 9$ to $14 \cdot 2)$ \\
\hline
\end{tabular}

$22 / 100000 /$ year was evident for both sexes at age 12 years (fig 2). There were no statistical differences in the age at diagnosis between the sexes in the 4 years and under and 5-9 year age groups. In the 10-14 year age group the 363 boys were significantly older at diagnosis than the 302 girls (mean ages boys $12 \cdot 6$ years, girls $12 \cdot 2$ years; Mann-Whitney $U$ test, $p=0 \cdot 0001$ ). There was no significant difference between the numbers of boys and girls in the 4 years and under, 5-9 year, and 10-14 year age groups $\left(\chi^{2}=0 \cdot 32\right)$.

When log linear regression was performed on the incidence rates for each sex within the three five year age groups (table II) the effect of sex was not significant $\left(\chi^{2}=0.036\right)$. The effect for trend across the age groups was, however, significant $\left(\chi^{2}=4.56, p<0.05\right)$, with an odds ratio of $1 \cdot 34$ - that is, the incidence rate increased at each age group by a factor of $1 \cdot 34$.

The incidence rates published by Bloom et al were for children with insulin dependent diabetes diagnosed at 15 years and under. ${ }^{3}$ We are grateful to the British Diabetic Association for access to and permission to use unpublished data on the number of cases of diabetes in children aged 14 years and under diagnosed by 1 year of age in 1973 and 1974. In Bloom et al's study the reference population figures used to calculate incidence rates were based on the 1971 census. We therefore used 1971 census figures for the British Isles to calculate the incidence rates using the mean of the number of cases diagnosed in each five year age group for 1973 and 74. ${ }^{11}$ When the number of cases diagnosed in each age group in 1988 was compared with the mean number of cases diagnosed in 1973-4, there seemed to be a significantly higher proportion of cases in children under the age of 5 years diagnosed in $1988(25 \%$, $404 / 1600)$ than in $1973-4(19 \%, 202 / 1056)$. Log linear regression was then used to study the incidence rates in each age group rather than the crude numbers for the two studies (table III): a significant year effect $\left(\chi^{2}=5 \cdot 45\right.$, $\mathrm{p}<0.05)$ and a significant age trend $\left(\chi^{2}=4.95, \mathrm{p}<0.05\right)$ were found. There was, however, no interaction between these two factors, showing that the same slope for age was applicable in both 1973-4 and 1988 $\left(\chi^{2}=0 \cdot 28\right.$, not significant $)$. The same statistical results were applicable when the data were divided by sex.

\section{MONTH OF DIAGNOSIS}

There were considerable variations in the numbers of cases diagnosed each month; most cases were diagnosed during February (155) and March (153), and least during May (103) and June (107). We did tests for seasonal trend ${ }^{23}$ on the three five year age groups, and the results suggested that the deviations

TABLE III -Number (\%) of cases and incidence of insulin dependent diabetes in children age 14 years and under during $1973-4$ and 1988 by five year age group

\begin{tabular}{|c|c|c|c|c|c|c|}
\hline \multirow[b]{2}{*}{$\begin{array}{l}\text { Age at diagnosis } \\
\text { (years) }\end{array}$} & \multicolumn{3}{|c|}{$1973-4$} & \multicolumn{3}{|c|}{1988} \\
\hline & $\begin{array}{c}\text { No }(\%) \text { of } \\
\text { population }\end{array}$ & $\begin{array}{c}\text { Mean No }(\%) \\
\text { of cases }{ }^{\star \star}\end{array}$ & $\begin{array}{c}\text { Incidence } \\
\text { (per 100000) }\end{array}$ & $\begin{array}{c}\text { No }(\%) \text { of } \\
\text { population }\end{array}$ & No $(\%)$ of cases & $\begin{array}{c}\text { Incidence } \\
(\text { per } 100000)\end{array}$ \\
\hline $\begin{array}{l}\leqslant 4 \\
5-9 \\
10-14\end{array}$ & $\begin{array}{l}4799933(34) \\
4964438(35) \\
4467194(31)\end{array}$ & $\begin{array}{l}202(19) \\
375(36) \\
479(45)\end{array}$ & $\begin{array}{r}4 \cdot 2 \\
7 \cdot 6 \\
10 \cdot 7\end{array}$ & $\begin{array}{l}4082438(35) \\
3980467(34) \\
3756265(32)\end{array}$ & $\begin{array}{l}404(25) \\
528(33) \\
668(42)\end{array}$ & $\begin{array}{r}9 \cdot 9 \\
13 \cdot 3 \\
17 \cdot 8\end{array}$ \\
\hline Total & $14231565(100)$ & $1056(100)$ & $7 \cdot 4$ & $11819170(100)$ & $1600(100)$ & $13 \cdot 5$ \\
\hline
\end{tabular}

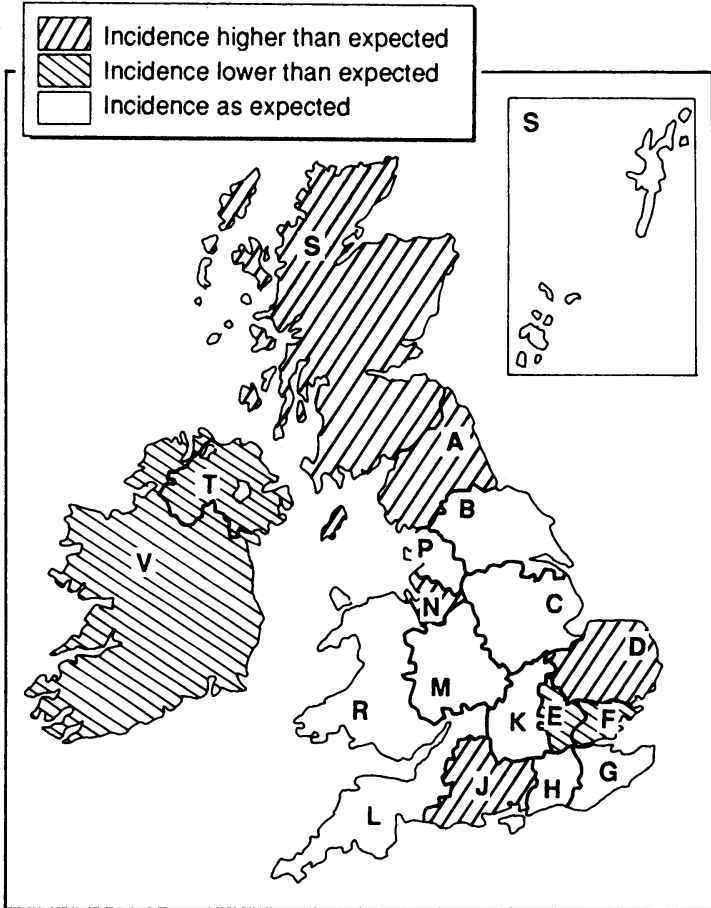

FIG 1 -Relative regional incidence rates for diabetic children less than 15 years old at diagnosis in each region in the British Isles from 1 fanuary to 31 December 1988 compared with national incidence rate (see table I)

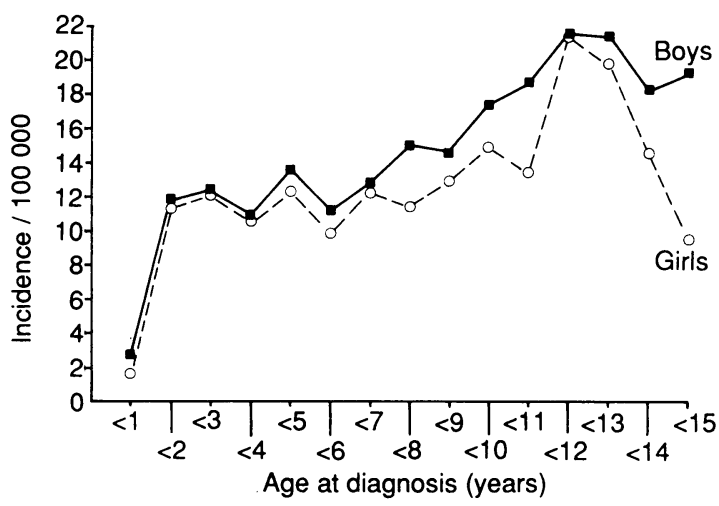

FIG 2-Age specific incidence of diabetes by age at diagnosis in 1988 for 837 boys and 763 girls

from a uniform seasonal incidence were significant at the $5 \%$ level for the two younger age groups, 4 years and under and 5-9 years, and at the $1 \%$ level for the children aged 10-14 years at diagnosis (KolmogorovSmirnov type statistic $\mathrm{V}_{\mathrm{N}}=1 \cdot 42,1.53$, and $2 \cdot 19$ respectively).

\section{Discussion}

This study was prompted by reports that the incidence of diabetes is increasing in northern Europe ${ }^{124-28}$ and that environmental factors may play a part in the development of the disease. ${ }^{29}{ }^{30}$ The incidence rate of insulin dependent diabetes in children aged 14 years and under at diagnosis for the British Isles in 1988 was $13 \cdot 5 / 100000$ /year; this falls midway between 
the lowest and highest reported by international studies, and is considerably higher than that of $7 \cdot 7 / 100000 /$ year found in 1973-4 in the British Diabetic Association's register ${ }^{3}$ (15 years and under, calculated $95 \%$ confidence interval $7 \cdot 2$ to $8 \cdot 1 / 100000$ ). It is impossible to estimate the case ascertainment for the British Diabetic Association's study, but it was probably unsatisfactory because it relied on the voluntary reporting of cases by hospital doctors. Our method of collecting information from consultant paediatricians by using active reporting through the British Paediatric Surveillance Unit and requesting the help of specialist nurses, health visitors, and physicians gave an ascertainment of about $90 \%$ (appendix). The British Diabetic Association's study would have had more underreporting than our study so that the actual difference in incidence rates between 1973-4 and 1988 was probably less than the above figure. Nevertheless, even if the ascertainment in the 1973-4 British Diabetic Association's study were as low as $60 \%$, giving an estimated corrected value of an incidence rate of $11 \cdot 2 /$ $100000 /$ year (estimated $95 \%$ confidence interval $10 \cdot 3$ to $11 \cdot 3 / 100000 /$ year) for children under the age of 16 years at diagnosis, there would seem to have been a real increase in the national incidence rate to $13 \cdot 5 / 100000$ / year in 1988 in children under the age of 15 years at diagnosis.

Although there were large differences in the regional incidence rates among the 18 regions in the British Isles, there was no obvious geographical pattern to the disease when the country was thus partitioned. Nine regions showed incidence rates that were no different from the national rate when the data were standardised for age and sex: four were lower than expected, and five were higher than expected. The differences in regional incidence rates could have been a reflection of the monthly response rates to the surveillance unit from paediatricians in different areas. To address this possible methodological flaw we studied the response rates of paediatricians in each region for $1988^{31}$ and the proportion of the total number of children under the age of 16 years at diagnosis reported for each region, and found no relation between them $(r=-0.02$, not significant). The mean response rate to the surveillance unit for 1988 was $89 \%$ (range $85-97 \%$ ).

In Scotland Patterson et al showed an increasing mean incidence rate of diabetes in children aged 18 years and under from $13 \cdot 8 / 100000 /$ year $(1968-76)$ to $21 \cdot 0 / 100000 /$ year $(1977-83){ }^{45}$ These figures were estimated from computerised hospital admission data, using a correction factor to allow for the fact that such data do not distinguish between new and readmitted patients. Our highest regional incidence rate was in Scotland: the rate of $19 \cdot 8 / 100000 /$ year was higher than the data of Patterson et al for 1977-83 might suggest for children aged 14 years and under. Burden et al have reported that the incidence rate in children aged 14 years and under in Leicestershire has increased from $3 \cdot 8 / 100000 /$ year $(1951-60)$ through $5 \cdot 3 / 100000 /$ year (1961-70) to $10 \cdot 6 / 100000 /$ year $(1971-80){ }^{6}$ Our regional incidence rate of $13 \cdot 5 / 100000 /$ year for the wider area of Trent Regional Health Authority (which includes Leicestershire) is higher still. Although it is not possible to make direct comparisons between our study and those from Scotland and Leicestershire because of the differences in age range and catchment area respectively, our incidence rates suggest that there has been a further increase in these two areas during the past decade.

On average, at least one child under the age of 5 years had diabetes diagnosed each day during 1988 (404 children). Data from the British Diabetic Association's register show that during the two years 1973 and 1974 only $19 \%$ of all new patients were under the age of 5 years. In our study a quarter of the children were aged 4 years and under at diagnosis. Although more very young children had diabetes diagnosed in 1988 than 15 years ago, this may be explained by the differences in the populations in each age group. There has been a decreasing birth rate in England and Wales over the past two decades, with the number of children under the age of 16 years falling by around a fifth between 1971 and 1988.32 In 1988, although the number of under $5 \mathrm{~s}$ was lower than in 1973-4, the proportion at risk was higher (table III). Analysis of the interaction between age trend and year effect showed that for both 1973-4 and 1988 the slope of the increase in incidence across the age groups was the same, showing that the increase in incidence rate during the 15 years had occurred in all age groups and for both sexes. The peak incidence at the beginning of puberty, presumably exacerbated by large changes in hormonal activity that may damage already weakened islet cells, agrees with other studies. ${ }^{26} 30$

The seasonal variation in the development of insulin dependent diabetes seems to be consistent in many countries in northern Europe with a winter peak and summer trough for some age groups and possibly less variation in younger children. ${ }^{24-26}$ In our study we found that the seasonal variation was present in all age groups but particularly in the children aged 10-14 years at diagnosis.

There are limited possibilities of validating the ascertainment of insulin dependent diabetes in the British Isles (appendix). Only 58\% (52/89) of cases known to the study administrator were identifiable from the Hospital Activity Analysis listing of the Northern Regional Health Authority and 74\% (56/76) from the listing of the South Western Regional Health Authority. In 1988, 57/165 (35\%) of children with newly diagnosed diabetes reported to the study and admitted to hospitals in the two regions were not identifiable on the Hospital Activity Analysis listings. This shows the difficulty of using regional computerised systems to validate the numbers of children admitted to hospital with a diagnosis of insulin dependent diabetes and corroborates other reports on the inaccuracy of these data. ${ }^{33} 34$

Nevertheless, we estimated an ascertainment of $90 \%$ in this national survey, confirming that the British Paediatric Surveillance Unit does offer a robust and meaningful system for the study of the incidence of uncommon diseases in childhood. These data may therefore serve as a baseline for future research into the epidemiology of insulin dependent diabetes in the British Isles.

This study was supported by the British Diabetic Association, with a grant from Nordisk-UK to support preparatory pilot studies. We thank the British Paediatric Surveillance Unit for its collaboration (funded by a grant from The Children Nationwide Medical Research Fund); all the paediatricians, physicians, and nurses for reporting cases; Dr P Bingley (Bart's-Oxford family study); Mrs M Mair (Scottish Study Group for the Care of Young Diabetics); the regional health authority statisticians (particularly Ms K R Denham and $\mathrm{Mr}$ I Longdon and their colleagues at the Northern and South Western Regional Health Authorities respectively); Mrs J-A Evans for statistical advice; Mrs S Redmond at the British Diabetic Association for her help with contacting the specialist nurses and health visitors; and Dr E A M Gale and Professor R J Jarrett for their advice on the study design.

\section{Appendix: Ascertainment and validation} METHOD

The statistical officers of each regional health authority in England and Wales were asked to provide restricted information (excluding names) on all children under the age of 16 years who had been admitted to hospital with an ICD code of 250 from 1 January 1980 (the year after the coding was changed) to 31 December 1988. The implementation of the Körner system after 1986 meant that the data from some 
regions were incomplete. The hospital activity analyses and patient information systems do not distinguish between first and subsequent admissions, but it would have been possible to eliminate most cases diagnosed before 1 January 1980 and to identify cases diagnosed within the correct time period which were unknown to the study administrator.

To have used this system of validation it would have been necessary to confirm with each admitting consultant that a "new" case had been diagnosed during 1988, although this method still would not have identified children who had been admitted with insulin dependent diabetes before 1980 and not readmitted before 1988 . In practice, it was not possible to obtain lists of cases from some regions without the specific permission of every consultant. As this would have necessitated a considerable workload for the regions' statistical officers and their colleagues and may have taken many months we decided to restrict the examination in detail to information from two regions that allowed the identification of possible new cases. The information systems manager of the Northern Regional Health Authority agreed to contact consultan paediatricians and physicians identified with an admission for insulin dependent diabetes after 1980 that fell within our criteria and asked them to confirm the case and return the information to Bristol. Consultant paediatricians and physicians in the South Western Regional Health Authority were also identified and contacted directly by JDB. Children in these two regions confirmed as new cases unknown to this study were not included in the analysis so as not to bias the interregional comparisons of data.

RESULTS

Of the 93 children under the age of 15 years at diagnosis during 1988 in the Northern region, three were from the Isle of Man and one was not admitted to hospital at diagnosis. Of the remaining 89 cases, only 52 known to the study were listed by the Northern region's Hospital Activity Analysis (58\%), 37 known to the study were not on the listing (42\%), and further 51 unknown to the study could have had newly diagnosed diabetes. After contacting the consultants about these possible new cases confirmation of 27 cases was received: 16 cases had been diagnosed before 1988 , and there were 11 cases unknown to the study administrator who were first admitted with insulin dependent diabetes during 1988 The ICD code of one other case was found to be incorrect, and no information was available for 23 because of lack of or incomplete response from the consultants. Similarly, in the South Western region one patient was not admitted at diagnosis, 56 of the remaining 76 cases $(74 \%)$ were confirmed by the Hospital Activity Analysis listing, and 20 cases known to the study were not on the listing. Of 48 possible new case in children under 15 years, three had been incorrectly coded and information was not available on 22. Of the remaining 23 cases, 14 had been diagnosed before 1988 and nine children were first admitted with insulin dependent diabetes during 1988. The extra cases identified by the hospital activity analyses represent a shortfall of at least $10 \%$. This would suggest an ascertainment of not more than $90 \%$.

1 Reunanen A, Akerblom HK, Kaar M-L. Prevalence and ten-year (1970-1979) incidence of insulin-dependent diabetes mellitus in children and adolescents in Finland. Acta Paediatr Scand 1982;71:893-9.
2 Matsuura N, Fukushima N, Fukita $\mathrm{H}$, et al. Epidemiologic survey of juvenileonset insulin dependent diabetes mellitus (IDDM) in Hokkaido, Japan, 1973-1981. Tohoku f Exp Med 1983;141(suppl):181-9.

3 Bloom A, Hayes TM, Gamble DR. Register of newly diagnosed diabetic children. BMF 1975;3:580-3.

4 Patterson CC, Thorogood M, Smith PG, et al. Epidemiology of type I (insulindependent) diabetes in Scotland 1968-76: evidence of an increasing incidence. Diabetologia 1983;24:238-43.

5 Patterson CC, Smith PG, Webb J, et al. Geographical variation in the incidence of diabetes mellitus in Scottish children during the period 1977-1983. Diabetic Med 1988:5:160-5.

6 Burden AC, Hearnshaw JR, Swift PG. Childhood diabetes mellitus: an increasing incidence. Diabetic Med 1989;6:334-6.

7 Hall SM, Glickman M. The British Paediatric Surveillance Unit. Arch Dis Child 1988;63:344-6.

8 British Diabetic Association Directory of nurses with a special interest in diabetes. London: BDA, 1987.

9 Barclay RP, Craig JO, Galloway CA, Richardson JE, Shepherd RC, Smail PJ The incidence of childhood diabetes in certain parts of Scotland. Scot Med 1988:33:237-9.

10 Bingley PJ, Gale EAM. Incidence of insulin dependent diabetes in England: a study in the Oxford region 1985-6. BMF 1989;298:558-60.

11 Office of Population Censuses and Surveys. Census 1971 summary tables ( $1 \%$ sample Great Britain). London: HMSO, 1973.

12 Census Office. Census of population 1971: summary tables for Northern Ireland. Belfast: HMSO, 1975.

13 Central Statistics Office. Census of population of Ireland 1971. Dublin: Stationery office, 1973. (Vol 2.)

14 Office of Population Censuses and Surveys. Key population and vital statistics. Series V5. London: HMSO, 1990. (No 15.)

15 Registrar General Scotland. 1988 population estimates Scotland. Edinburgh: HMSO, 1989 .

16 General Register Office (Northern Ireland). 67th annual report of the registra general for Northern Ireland. Belfast: HMSO, 1990.

17 Central Statistics Office. Census 86: summary population report. Dublin Stationery Office, 1987.

18 Isle of Man Treasury. Isle of Man: interim census 1986. Isle of Man: Isle of Man Government, 1986

19 State Population Migration Committee. Guernsey census 1986. States of Guernsey: States of Guernsey, 1987.

20 Economic Advisors Office. Report of census for 1986. Jersey: States Greffe, 1987.

21 Armitage P. Berry. G. Statistical methods in medical research. 2nd ed. London: Blackwell Scientific Publications, 1987.

22 Lentner C, ed. Geigy scientific tables. Basle: Ciba-Geigy, 1982. (Vol 2.)

23 Freedman LS. The use of a Kolmogorov-Smirnov type statistic in testing hypotheses about seasonal variation. $\mathcal{F}$ Epidemiol Community Health 1979 33:233-8

24 Dahlquist G, Blom L, Holmgren G, et al. The epidemiology of diabetes in Swedish children 0-14 years-a six-year prospective study. Diabetologia 1985;28:802-8

25 Rewers M, LaPorte RE, Walczak M, Dmochowski K, Bogaczynska E Apparent epidemic of insulin-dependent diabetes mellitus in midwester Poland. Diabetes 1987;36:106-13.

26 Joner G, Sovik $O$. Increasing incidence of diabetes mellitus in Norwegian children 0-14 years of age 1973-82. Diabetologia 1989;32:79-83.

27 Nystrom L, Dahlquist G, Rewers M, Wall S. The Swedish childhood diabetes study. An analysis of the temporal variation in diabetes incidence 1978-1987. Int I Epidemiol 1990;19:141-6.

28 Bingley PJ, Gale EAM. Rising incidence of IDDM in Europe. Diabetes Care 1989;12:289-95.

29 Diabetes Epidemiology Research International. Preventing insulin dependent diabetes mellitus: the environmental challenge. BMF 1987;295:479-81.

30 Soltesz G, Madacsy D, Bekefi D, Danko I. Rising incidence of type 1 diabetes in Hungarian children (1978-1987). Diabetic Med 1990;7:111-4.

31 British Paediatric Surveillance Unit. Third annual report 1988-89. London: BPSU, 1989.

32 Jones C, Armitage B. Population change within area types: England and Wales, 1971-1988. Population Trends 1990;60:31.

33 Williams DRR, Fuller JH, Stevens LK. Validity of routinely collected hospita admissions data on diabetes. Diabetic Med 1989;6:320-4

34 Leslie PJ, Hepburn DA, Patrick AW, et al. The morbidity of diabetes is significantly under-estimated by hospital in-patient statistics based on discharge summaries. Diabetic Med 1990;7(suppl 2): 24A.

(Accepted 4 December 1990)

\section{ONE HUNDRED YEARS AGO}

The subject of unqualified practice is at all times one of grave concern to members of the medical profession, and the attention of the public will, we think, be awakened by the remarks of the coroner in some recent inquiries at Manchester as reported in the Manchester Courier. The coroner is reported to have characterised this unqualified practice as most reprehensible, and to have expressed the opinion that there was a great deal of it going on, and that it was simply a swindle on the poor. In one of the inquiries referred to, it appeared that the deceased had been attended in her last illness by an unqualified assistant to a medical man; and although it was not suggested that the deceased had been improperly treated, we are naturally led to consider the subject of the employment of unqualified assistants generally. There is no doubt that, according to law, the duties of such an employe should be confined to his master's house; he should be merely the ministering hand under the directing brain of the qualified man, acting only under his direct personal supervision. To such an extent only can the employer legally recover his charges for services rendered. If this rule were stringently observed, we should hear less of cases of unqualified assistants who (having attained the confidence of their employer's patients) commence to practise on their own account, in some cases, we are sorry to say, under the alleged cover of a qualified man. This kind of unqualified practice could scarcely happen if greater care were exercised to confine the employment of an unqualified assistant within its legal limits. (British Medical fournal 1891;i:363) 